\title{
Mathematical Model and Simulation of Magnetic Levitation Spherical Driving Joint with Inverse System Decoupling Control
}

\author{
Yang Yanneng \\ College of Mechanical Engineering Yangzhou University \\ Yangzhou University,YZU \\ Yangzhou, China, 15050715367 \\ yangyanneng@163.com
}

\author{
Zeng Li \\ College of Mechanical Engineering Yangzhou University \\ Yangzhou University,YZU \\ Yangzhou, China, 13665203656 \\ lizengcf@163.com
}

\begin{abstract}
The paper presents a new magnetic levitation spherical driving joint. It analyses the theory of air-gap magnetic of the driving joint and the mechanism of the generation of the magnetic levitation force and electromagnetic torque which based on the principle of reluctance motor. The mathematical model and the inverse system decoupling model of the driving joint have been established. The decoupling linearization and the state feedback closed-loop control system also have been achieved in it. The research of the result of system simulation provides us the decoupling characteristic, the dynamic characteristic and capacity of resisting disturbance of the driving joint system.
\end{abstract}

Keywords- spherical electric machines; magnetic levitation; spherical driving joint; mathematical model; decoupling control; capacity of resisting disturbance

\section{INTRODUCTION}

A spherical joint, also called multi-freedom joint, has two or three rotating freedom. It has high mechanical integration. So the spherical joint is widely used in electronics, machinery industries, the life sciences etc. ${ }^{[1]}$ The existing multi-freedom joint is driven by two or more motors and mechanical devices, therefore it is big, complex and restricted in application. ${ }^{[2,3]}$ In high-speed and ultra high-speed multi-freedom joint device, there exists the wear problem of bearing. It increases the friction in joint, and causes the components heating, and even causes the lots of dynamic characteristics. Therefore, the paper presents a two or multi-degree-of-freedom magnetic levitation spherical reluctance-driving joint, ${ }^{[4,5]}$ which has highly integration, simple structure, non-wear, high accuracy and good dynamic performance, and studies the working mechanism and the decoupling control of it.

\section{The BASIC STRUCTURE AND WORKING PRINCIPLE OF MAGNETIC LEVITATION SPHERICAL DRIVING JOINT}

\section{A. Structure Of Magnetic levitation spherical Driving Joint}

Magnetic levitation spherical joints are made up of multiple joints with motor stator and joint of spherical rotor with turning arm etc, the three-dimensional structure signal is shown in Fig. 1. Joint rotor is surrounded by the joints of the motor stators; four stators are designed to be symmetric distribution in the equator line position of joint of spherical rotor, among the

The China Natural Science Foundation for this project. Item Number: 50975249.And the Fundamental Research of Natural Science Foundation for Universities of Jiangsu Province: 08KJB460008. And the Fundamental Research of Natural Science Foundation for Universities of Jiangsu Province: 09KJD460006. stators, the stator 1 and the stator 3 are symmetrical about spherical rotor and keep coaxial along the $\mathrm{X}$ axis.The stator 2 and the stator 4 are symmetrical about spherical rotor and keep coaxial along the $\mathrm{Y}$ axis. The stator 5 arranges the top of spherical rotor and keeps coaxial with the $\mathrm{Z}$ axis.

\section{B. Principle Of Magnetic levitation spherical Driving Joint}

The stator 1 and the stator 3 drive rotor spinning around the $\mathrm{X}$ axis and make the rotor in the $\mathrm{X}$ axis stability of maglev force. The stator 2 and the stator 4 drive rotor spinning around the $\mathrm{Y}$ axis and make the rotor in the $\mathrm{Y}$ axis stability of maglev force. The stator 5 drives rotor spinning around the $\mathrm{Z}$ axis and makes the rotor in the $\mathrm{Z}$ axis stability of maglev force. Magnetic spherical driving joint rotor is the external envelope saliency sphere of spherical rotor, and each joint stator is made up of several saliency columns, the tops of column are to constitute the internal envelope sphere and keep parallel with the external envelope sphere which keeps balance position. According to the theory of reluctance motor rotor, joint stator saliency is around polyphase winding which make rotor whirling. Each phase windings after electrify produces electromagnetic torque to drive spherical rotor and also provides radial magnetic levitation force for the spherical rotor.

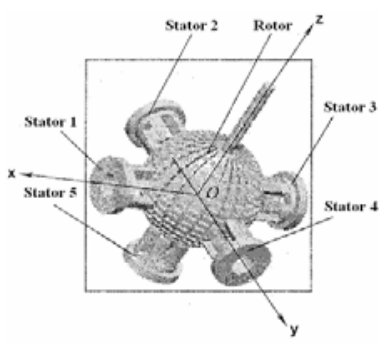

Fig.1. Structure of spherical driving joint with magnetic levitation

\section{The Mathematical Model of Magnetic LEVITATION SPHERICAL DRIVING JOINT}

A. The motion equation of magnetic levitation spherical driving joint

Taking three-phase winding for example, if the magnetic levitation spherical driving joint in a coordinate direction (such as the $\mathrm{X}$ axis), the two stators which is symmetrical in rotor 
drive the stator suspend and rotate along the coordinates. ${ }^{[7]}$ Supposing the stability of the suspension rotor under the action of interference offset for $\mathrm{x}$ in the coordinate, In order to make the rotor restored to its original balance position, in the controller, the wind current $i_{1}$ of the reduced stator which is near the clearance will decrease, the wind current $i_{2}$ of the added stator which is near the clearance will increase. Magnetic levitation spherical driving joints in the $\mathrm{X}$ axis produce the electromagnetic levitation force is:

$$
\mathrm{F}_{\mathrm{x}}=\left[\frac{\mathrm{i}_{1}^{2}}{2\left(\mathrm{~g}_{0}-\mathrm{x} \cos \varphi_{0}\right)^{2}}-\frac{\mathrm{i}_{2}^{2}}{2\left(\mathrm{~g}_{0}+\mathrm{x} \cos \varphi_{0}\right)^{2}}\right] \cdot \mathrm{K}_{\mathrm{f}}(\Psi)
$$

Where

$\mathrm{K}_{\mathrm{f}}(\Psi)=\frac{1}{2} \mathrm{~N}^{2} \mathrm{R}^{2} \pi \cos \varphi_{0} \sum_{\mathrm{k}=0}^{2} \int_{\varphi_{1}}^{\varphi_{2}}\left[1+\mathrm{K} \cos 2\left(\varphi+\Psi-\frac{2 \mathrm{k} \pi}{3}\right)\right] \sin \varphi \mathrm{d} \varphi$

Due to the excursion of the rotor, the total electromagnetic torque of the magnetic levitation spherical driving joint along the $\mathrm{X}$-axis is:

$$
\mathrm{M}_{\mathrm{x}}=\frac{\mathrm{i}_{1}^{2} \mathrm{~K}_{\mathrm{m}}(\Psi)}{2\left(\mathrm{~g}_{0}-\mathrm{x} \cos \varphi_{0}\right)}+\frac{\mathrm{i}_{2}^{2} \mathrm{~K}_{\mathrm{m}}(\Psi)}{2\left(\mathrm{~g}_{0}+\mathrm{x} \cos \varphi_{0}\right)}
$$

Where

$$
\mathrm{K}_{\mathrm{m}}(\Psi)=-\mathrm{N}^{2} \mathrm{R}^{2} \mathrm{~K} \pi \sum_{\mathrm{k}=0}^{2} \int_{\varphi_{1}}^{\varphi_{2}} \sin \varphi \sin 2\left(\varphi+\Psi-\frac{2 \mathrm{k} \pi}{3}\right) \mathrm{d} \varphi
$$

According to Newton's second law, the motion equation of the spherical rotor along the $\mathrm{X}$-axis movement and rotating around the $\mathrm{X}$-axis is:

$$
\left\{\begin{array}{c}
\mathrm{m} \cdot \frac{\mathrm{d}^{2} \mathrm{x}}{\mathrm{dt}^{2}}=\left[\frac{\mathrm{i}_{1}^{2} \cdot \mathrm{K}_{\mathrm{f}}(\Psi)}{2\left(\mathrm{~g}_{0}-\mathrm{x} \cos \varphi_{0}\right)^{2}}-\frac{\mathrm{i}_{2}^{2} \cdot \mathrm{K}_{\mathrm{f}}(\Psi)}{2\left(\mathrm{~g}_{0}+\mathrm{x} \cos \varphi_{0}\right)^{2}}\right]+\mathrm{F}_{\mathrm{d}} \\
\mathrm{J} \cdot \frac{\mathrm{d}^{2} \Psi}{\mathrm{dt}^{2}}=\frac{\mathrm{i}_{1}^{2} \mathrm{~K}_{\mathrm{m}}(\Psi)}{2\left(\mathrm{~g}_{0}-\mathrm{x} \cos \varphi_{0}\right)}+\frac{\mathrm{i}_{2}^{2} \mathrm{~K}_{\mathrm{m}}(\Psi)}{2\left(\mathrm{~g}_{0}+\mathrm{x} \cos \varphi_{0}\right)}+\mathrm{M}_{\mathrm{d}}
\end{array}\right.
$$

Where $\mathrm{m}$ is the quality of the spherical rotor, $\mathrm{J}$ is the rotational inertia of the spherical rotor; Fd is disturbing force and $\mathrm{Md}$ is the moment which the spherical rotor is to bear expect electromagnetic levitation force (moment).

So the magnetic levitation force of the magnetic spherical driving joints on the $\mathrm{X}$-axis and the electromagnetic torque of the magnetic spherical driving joints around the $\mathrm{X}$ axis are related to the clearance $\left(\mathrm{g}_{0} \pm \mathrm{x} \cos \varphi_{0}\right)$ between the rotor convex poles and the stator convex poles and the resulting current winding $i$, therefore through changing winding currents it can control the stability of the suspension of the spherical rotor along the $\mathrm{X}$ axis and the rotation movement around the $\mathrm{X}$ axis.

The formula 3 can describe the dynamic mathematical model of the magnetic levitation spherical driving joint without regard to the factors of the winding; thus, the system is the nonlinear strong coupling system.

\section{B. The state equations of magnetic levitation spherical driving joint}

To using state space model system, magnetic levitation spherical joint is described:

$$
\left\{\begin{array}{c}
\&=f(X)+g(X) U \\
Y=h(X)
\end{array}\right.
$$

where

$$
\begin{aligned}
& \mathrm{X}=\left[\begin{array}{llll}
\mathrm{x} & \& & \Psi & \&
\end{array}\right]^{\mathrm{T}}=\left[\begin{array}{lllll}
\mathrm{x}_{1} & \mathrm{x}_{2} & \mathrm{x}_{3} & \mathrm{x}_{4}
\end{array}\right]^{\mathrm{T}}, \\
& \mathrm{U}=\left[\begin{array}{ll}
\mathrm{i}_{1}^{2} & \mathrm{i}_{2}^{2}
\end{array}\right]^{\mathrm{T}}=\left[\begin{array}{ll}
\mathrm{u}_{1} & \mathrm{u}_{2}
\end{array}\right]^{\mathrm{T}} \text {, } \\
& g(X)=\left[\begin{array}{ccccc}
0 & \frac{1}{m} \cdot \frac{\mathrm{K}_{\mathrm{f}}\left(\mathrm{x}_{3}\right)}{2\left(\mathrm{~g}_{0}-\mathrm{x}_{1} \cos \varphi_{0}\right)^{2}} & 0 & \frac{1}{\mathrm{~J}} \cdot \frac{\mathrm{K}_{\mathrm{m}}\left(\mathrm{x}_{3}\right)}{2\left(\mathrm{~g}_{0}-\mathrm{x}_{1} \cos \varphi_{0}\right)} \\
0 & -\frac{1}{\mathrm{~m}} \cdot \frac{\mathrm{K}_{\mathrm{f}}\left(\mathrm{x}_{3}\right)}{2\left(\mathrm{~g}_{0}+\mathrm{x}_{1} \cos \varphi_{0}\right)^{2}} & 0 & \frac{1}{\mathrm{~J}} \cdot \frac{\mathrm{K}_{\mathrm{m}}\left(\mathrm{x}_{3}\right)}{2\left(\mathrm{~g}_{0}+\mathrm{x}_{1} \cos \varphi_{0}\right)}
\end{array}\right]^{\mathrm{T}} \\
& f(X)=\left[\begin{array}{llll}
x_{2} & \frac{1}{m} \cdot F_{d} & x_{4} & \frac{1}{J} \cdot M_{d}
\end{array}\right]^{T} \\
& \mathrm{~h}(\mathrm{X})=\left[\begin{array}{ll}
\mathrm{x}_{1} & \mathrm{X}_{4}
\end{array}\right]^{\mathrm{T}}
\end{aligned}
$$

The formula 4 describes the original system model of the magnetic levitation spherical driving joint system's nonlinear dynamics coupling system. According to the prototype model, we can get the inverse system model, so as to decoupling control for joint system.

\section{THE INVERSE SYSTEM MOdEl OF MAGNetiC LEVITATION SPHERICAL DRIVING JOINT}

Using literature ${ }^{[7]}$, it makes inversion for:

$$
\left\{\begin{array}{l}
=\frac{1}{\mathrm{~m}} \cdot \frac{\mathrm{u}_{1} \mathrm{~K}_{\mathrm{f}}\left(\mathrm{x}_{3}\right)}{2\left(\mathrm{~g}_{0}-\mathrm{x}_{1} \cos \varphi_{0}\right)^{2}}-\frac{1}{\mathrm{~m}} \cdot \frac{\mathrm{u}_{2} \mathrm{~K}_{\mathrm{f}}\left(\mathrm{x}_{3}\right)}{2\left(\mathrm{~g}_{0}+\mathrm{x}_{1} \cos \varphi_{0}\right)^{2}}+\frac{1}{\mathrm{~m}} \cdot \mathrm{F}_{\mathrm{d}} \\
\&=\frac{1}{\mathrm{~J}} \cdot \frac{\mathrm{u}_{1} \mathrm{~K}_{\mathrm{m}}\left(\mathrm{x}_{3}\right)}{2\left(\mathrm{~g}_{0}-\mathrm{x}_{1} \cos \varphi_{0}\right)}+\frac{1}{\mathrm{~J}} \cdot \frac{\mathrm{u}_{2} \mathrm{~K}_{\mathrm{m}}\left(\mathrm{x}_{3}\right)}{2\left(\mathrm{~g}_{0}+\mathrm{x}_{1} \cos \varphi_{0}\right)}+\frac{1}{\mathrm{~J}} \cdot \mathrm{M}_{\mathrm{d}}
\end{array}\right.
$$

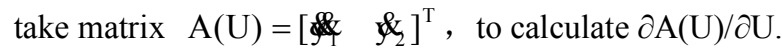

Because $\operatorname{rank}[\partial \mathrm{A}(\mathrm{U}) / \partial \mathrm{U}]=2$ is a nonsingular matrices, the relative degree of the magnetic levitation spherical driving joint is $\alpha=(21)$, and $\sum_{i=1}^{2} \alpha i=3<n, \quad(n=4)$, so the inverse system exists.

Order

$$
\left[\begin{array}{ll}
\& & \&
\end{array}\right]^{\mathrm{T}}=\varphi
$$

where $\varphi=\left[\begin{array}{ll}\varphi 1 & \varphi 2\end{array}\right]^{\mathrm{T}} \quad$ indicates the new system input.

According to the formula 5 and the formula 6 , it can get the control discipline of magnetic levitation spherical driving joint with the inverse system:

$\left\{\begin{array}{l}\mathrm{u}_{1}=\frac{2\left(\mathrm{~g}_{0}^{2}-\mathrm{x}_{1}^{2} \cos \varphi_{0}^{2}\right)^{2}\left(\mathrm{mD} \varphi_{1}+\mathrm{JB} \varphi_{2}+B \mathrm{M}_{\mathrm{d}}+\mathrm{DF}_{\mathrm{d}}\right)}{\mathrm{K}_{\mathrm{f}}\left(\mathrm{x}_{3}\right) \mathrm{K}_{\mathrm{m}}\left(\mathrm{x}_{3}\right) \mathrm{g}_{0}} \\ \mathrm{u}_{2}=\frac{2\left(\mathrm{~g}_{0}^{2}-\mathrm{x}_{1}^{2} \cos \varphi_{0}^{2}\right)^{2}\left(-\mathrm{mC} \varphi_{1}+J A \varphi_{2}+\mathrm{AM}_{\mathrm{d}}-\mathrm{CF}_{\mathrm{d}}\right)}{\mathrm{K}_{\mathrm{f}}\left(\mathrm{x}_{3}\right) \mathrm{K}_{\mathrm{m}}\left(\mathrm{x}_{3}\right) \mathrm{g}_{0}}\end{array}\right.$

where

$$
\begin{aligned}
& A=\frac{K_{f}\left(x_{3}\right)}{2\left(g_{0}-x_{1} \cos \varphi_{0}\right)^{2}}, B=\frac{K_{f}\left(x_{3}\right)}{2\left(g_{0}+x_{1} \cos \varphi_{0}\right)^{2}} \\
& C=\frac{K_{m}\left(x_{3}\right)}{2\left(g_{0}-x_{1} \cos \varphi_{0}\right)}, D=\frac{K_{m}\left(x_{3}\right)}{2\left(g_{0}-x_{1} \cos \varphi_{0}\right)}
\end{aligned}
$$


The formula 7 constitutes the magnetic levitation spherical driving joint system which makes $\varphi 1, \varphi 2$ for input and $u 1, u 2$ (or $\mathrm{i}_{1}=\sqrt{\mathrm{u}_{1}}, \mathrm{i}_{1}=\sqrt{\mathrm{u}_{1}}$ ) for output with the state feedback linearization control algorithm of 4 order integral inverse system decoupling.

\section{THE Linear DeCOUPLing CONTROL AND SimUlation PERFORMANCE ANALYSIS OF THE SYSTEM}

According to the formula 7 , the formula 4, the simulation model of magnetic levitation spherical driving joint with inverse system decoupling and comprehensive correction is established. According to the control strategy of spherical switched reluctance motor with magnetic levitation, establish the module of motor, module of speed control, module of current control and module of rotor position calculation and so on by Matalab/Simunik software. To substitute the specific parameters for system simulation, it can get the simulation curve which likes Fig. 2 to Fig. 4.

\section{A. The float process of spherical rotor}

Fig. 2 is the spherical rotor float from natural place after inverse system decoupling and comprehensive correction, when to be unloaded, the initial value of the dynamic response of the direction of a degree of freedom is $\mathrm{x}_{0}=-2 \times 10^{-4} \mathrm{~m}$ along the $\mathrm{X}$ axis. According to the result of the simulation, we can find the overshoot of the system is $22 \%$ and the accommodation time is $1.7 \mathrm{~s}$. The radial position subsystem of the spherical rotor of the magnetic levitation spherical driving joint decoupling control system has good dynamic performance and static performance.

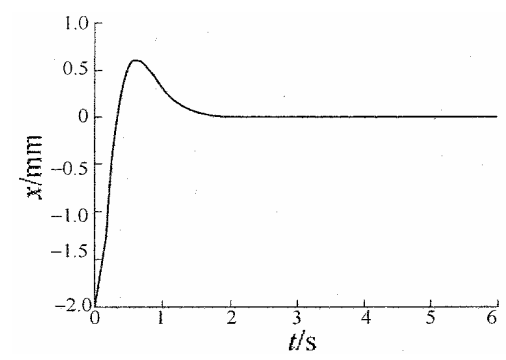

Fig. 2. The dynamic response of the rotor position

\section{B. The rotate speed response of spherical rotor}

Fig. 3 is the step response of the spherical rotor rotating along the $\mathrm{X}$-axis after inverse system decoupling and comprehensive correction, the expect speed is $1.2 \times 10^{5} \mathrm{r} / \mathrm{min}$. According to the result of the simulation, the rotating speed doesn't have overshoot and the accommodation time is $0.5 \mathrm{~s}$, the speed subsystem have good performance index.

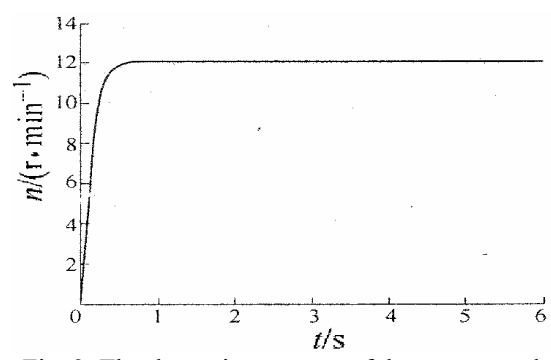

Fig. 3. The dynamic response of the rotor speed

\section{Dynamic decoupling performance}

Inverse system decoupling control made full use of all the system state variables, and because considering the coupling between subsystems, the dynamic performance is better. The rotating speed influences the radial position which likes Fig.4. Fig. 4(a) is the rotor speed state chart, after the rotating speed get the stable value $\left(1.2 \times 10^{5} \mathrm{r} / \mathrm{min}\right)$, it cuts down to $6 \times 10^{4} \mathrm{r} / \mathrm{min}$ when $\mathrm{t}=3 \mathrm{~s}$; when in the station of the puzzled decoupling, after using PID control strategy the dynamic process of the radial rotor position changing with the rotating speed likes Fig.4(b); after inverse system decoupling, the dynamic process of the spherical rotor position changing with the rotating speed by using the state feedback control strategy likes Fig. 4(c).

According to the result of simulation, if using PID control strategy, the radial rotor position will undulate while the rotating speed is changed. If using the state feedback control strategy, the radial position is unacted on the rotating speed and is always in balance.

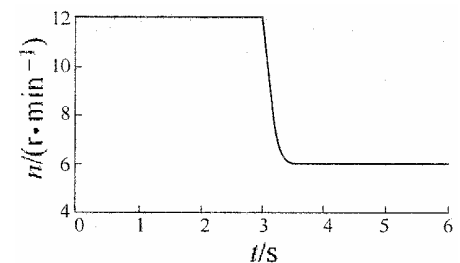

(a)

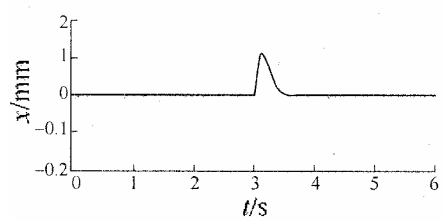

(b)

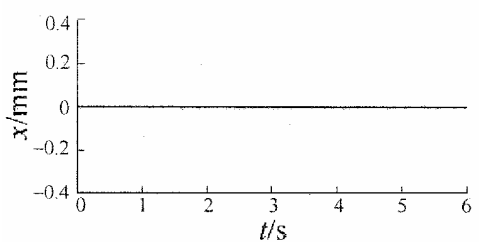

(c)

Fig. 4. The radial displacement by the influence of the rotating speed

\section{The relationship diagram between Electrical levitation force and axial displacement}

Figure 5 show the relationship diagram between electrical levitation force and axial displacement. From figure, we can see that the rotor displacement is largest at boot time. In order to get the rotor back to the equilibrium position quickly, the electrical levitation force in radial direction is largest, which is $240 \mathrm{~N}$. When motor rotor at balance position, due to inertia, rotor can't be stopped immediately to zero point, but pass a little, and then a force in the opposite direction will be acted on the rotor. So over a period of time, rotor will has a small oscillation in a central position and the force act on rotor changes in a very small range. Maintained motor within a small oscillations in central location, we can consider it achieve stability condition. 


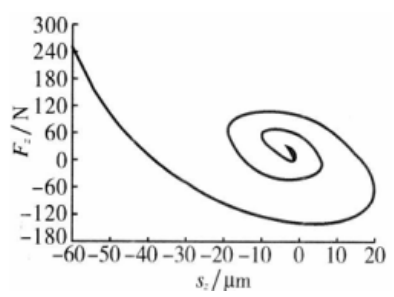

Fig.5 The relationship diagram between Electrical levitation force and axial displacement

\section{E. Interference Rejection of Rotor}

From figure 6, we can see that the spherical switched reluctance motor with magnetic levitation can back to the equilibrium position at short notice after disturbances. The all of it rising time less than $0.02 \mathrm{~s}$ and overshoot is small, have no oscillations. Thus shows that the motor suspension control system has a good ability to resist interference.

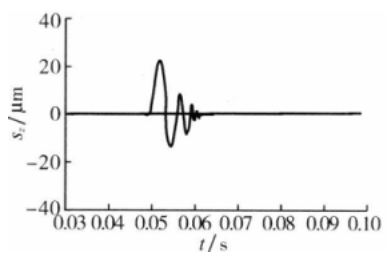

Fig. 6 Rotor simulation results when disturbed

\section{RESULTS}

The paper presents a new magnetic levitation spherical reluctance-driving joint. Based on the principle of magnetic reluctance motor, it analyzes the mechanism of the air-gap magnetic energy of the driving joints and the principle of electromagnetic levitation force and electromagnetic torque, and establishs the mathematical model of driving joint system and inverse system decoupling model. The paper decouples and linearizes the model of driving joint system and gives a station feedback closed-loop control method. The study describes the decoupling characteristics, dynamic response characteristics and capacity of resisting disturbance of the magnetic levitation spherical reluctance-driving joint system..

\section{REFERENCES}

[1] Wang Guangjian, Liang Xichang, Jiang Jiandong. The Present State and Developing Tendency of Robot Joint[J]. Journal of Mechanical Transmission, 2004.28(4):1-5.

[2] Wu Junfei, Zhou Guilian, Fu Ping. Research Progress of Drives Used in Robot Joint[J]. Journal of Qingdao Institute of Chemical Technology, 2002.23(3):54-58.

[3] Tan wei,Zhao Xifang, The Research and Development of Robots Directly Driven Technology, The Mechanical Engineer,2000.4:5 8

[4] Zeng Li, Zhang Dan, Dai Min. Maglev Spherical Reluctance Motor with Centripetal Thrust/Pull. China, ZL200920039032.7[P]. 2001-01.

[5] Zeng Li, Zhang Dan, Dai Min. Switch Reluctance Driving Joint with Magnetic Levitation. China, ZL200920039032.7[P]. 2001-01.

[6] Hu Yueming, The Theory and Application of The Nonlinear Control Systems[M],Beijing, Defense Industry Press,2005

[7] Li Chunwen, Miao Yuan,Feng Yuankun etc, The Inverse System Method of The Nonlinear System Control,( II )--Multivariable Control Theory[J], The Control and Decision,1997,11(12) 